\title{
Evidence-based coaching to enhance senior students' wellbeing and academic striving
}

\author{
Aylin Dulagil · Suzy Green · Madonna Ahern
}

\begin{abstract}
This study examined the impact of an evidence-based within subjects coaching intervention within an Australian high school. Participants were a cohort of 25 female high school students aged between 15 and 16 years (mean age $=15.9$ ). The coaching program was part of a broader positive education program conducted by the school. Participants took part in a tensession evidence-based coaching program (teacher facilitated) that included topics such as goal setting, mindfulness, coaching, and helpful self-talk. Pre and post measures were obtained for wellbeing, cognitive hardiness, trait hope, depression, anxiety, stress, and goal striving and goal achievement. Participants showed a significant increase in wellbeing, total trait hope, cognitive hardiness, and a significant decrease in depression, anxiety and stress. Participants also showed a significant increase in perceptions of successful striving towards personal goals. Scores on personal goal commitment, academic goal striving and academic goal commitment demonstrated a trend towards increased success in the post-intervention scores but did not achieve significance. This study uniquely considers evidence-based coaching as part of a broader positive education approach in an education setting. Limitations of the study and directions for future research are discussed.
\end{abstract}

Keywords: coaching, high school, positive education, positive psychology, wellbeing

\section{Introduction}

Schools have played a critical role in promoting wellbeing for some time. Approaches have moved from a focus on self-esteem in the 1970s, to social skills programs in the 1990s and resilience and anti-bullying programs in the 2000s (McGrath, 2009). More recently, schools have been recognized as important locations for the use of positive psychology, with the specific aim of increasing student wellbeing and building useful skills for promoting positive human development throughout the life span (Huitt, 2011; Gill, 2009; Clonan, Chafouleas, McDougal, \& Riley-Tillman, 2004; Green, 2014).

The wellbeing of adolescents is increasingly a salient concern for educators and can be defined as the combination of feeling good and functioning well (Huppert \& Johnson, 2010). Finding agreement about what constitutes adolescent (or student) wellbeing is difficult (Roffey, 2012). Roffey (2012), however, asserts that student wellbeing is "a sustainable emotional state characterized by (predominantly) positive mood, attitude and relationships at school, resilience, self-optimization and a high level of satisfaction with learning experiences" (p. 19). The recent NSW Department of Education and Communities, "Wellbeing Framework for Schools" (2015) document defines wellbeing as relating both to feeling good and functioning well (reflecting the distinction between hedonic and eudemonic wellbeing that has long occupied philosophers and 
psychologists). The document defines five domains in which wellbeing can be experienced: cognitive, emotional, social, physical, and spiritual.

Schools play an important role in shaping a student's wellbeing through educating teachers to provide experiences and opportunities that develop character and wellbeing. Schools are increasingly exploring more proactive approaches to adolescent wellbeing (van Nieuwerburgh, 2012), such as positive psychology and evidence-based coaching (Green, 2014). Focusing on initiatives that proactively target young people provides a double benefit: improving the wellbeing of young people, and providing them with the psychological tools to help them deal with life problems as they grow into adulthood.

It is widely recognized that schools are an important and influential environment for nurturing adolescents' psychological and physical health. Evidence is also now mounting to attest to the impact that student wellbeing has on academic performance (Waters, 2011). As such, schools are increasingly recognized for the role they play in nurturing the whole adolescent, and there has been a greater focus on teachers delivering wellbeing programs within schools (Waters, 2011). Within Australia, many schools are embracing whole-school approaches to "Positive Education" (Seligman, Ernst, Gillham, Reivich, \& Linkin, 2009; Green 2014), and teachers are undergoing extensive training in order to roll out such wellbeing programs to students (e.g., www.pesa.edu.au). Given that positive psychology aims to increase wellbeing, schools serve as a critical vehicle for promoting positive human development (Clonan et al., 2004; Green, 2014).

\section{Positive education}

Positive Education was formally defined as a field in 2009 (Seligman et al., 2009). Seligman et al. (2009) claim there is evidence for the constructive development of both traditional academic skills and skills "for happiness" (Seligman et al., 2009). The initiating premise for positive education was that wellbeing could be taught in schools to ameliorate subsequent mental health issues such as depression, and to increase life satisfaction, creative thinking and better learning (Seligman et al., 2009). However, there is also a growing evidence base to show that student wellbeing is positively associated with academic performance. A meta-analysis of 213 studies involving 270,034 students ranging from kindergarten to high school showed that school students taking part in social and emotional learning programs ranked 11 percentage points higher on academic achievement tests than did students who did not participate in such programs (Durlak, Weissberg, Dymnicki, Taylor, \& Schellinger, 2011).

Since that time, the definition of positive education has been expanded and refined. Green, Oades, \& Robinson (2011) posited that "applied positive psychology in education" provided a more useful definition of the range of interventions that may be applied within schools. Green further refined the definition of positive education as "the application of wellbeing science into an educational setting aimed at increasing the resilience and wellbeing of students, staff, and whole-school community" (Green, 2014). In addition to recognizing and addressing the evolution of terminology (i.e., "happiness" to "wellbeing"), this definition acknowledges the increasing application of related wellbeing sciences such as evidence-based coaching and neuroscience under the umbrella of positive education (Green, 2014).

Positive psychology and coaching psychology are complementary fields that share a common purpose, namely the enhancement of wellbeing (van Nieuwerburgh, 2012). Evidencebased coaching can be defined as "the intelligent and conscientious use of ... [up-to-date information from relevant, valid research, theory and practice] ... integrated with practitioner expertise in making decisions about how to deliver coaching" (Stober \& Grant, 2006, p. 6). 
Education in the 21st century has been conceptualized in a multi-dimensional way, and includes new technologies, new pedagogies, a nationalized curriculum, open learning spaces and enhanced teacher training. In addition, it is argued that schools play an important role in assisting adolescents to develop cognitive, social and emotional skills (Waters, 2011; 2014). As a result, a core component of modern schooling in both the private and state sector is the call for education to develop the whole student through social, emotional, moral and intellectual development (Cain \& Carnellor, 2008; Huitt, 2011). The desire to educate the whole student has emerged out of an environment that is complex and challenging; a world where more adolescents are experiencing mental health issues such as anxiety and depression (Waters, 2011). Models of academic achievement have long dominated the education landscape, and success has been associated with academic excellence (Norrish, 2015). Increasingly, the wellbeing of adolescents is becoming a salient concern for educators in the 21st century.

Positive education is growing globally, and schools in Australia are rapidly adopting positive approaches (see Gilman, Huebner \& Furlong (2009), for a comprehensive review of the research in this area). In particular, Australia has led the way, and may be considered a pioneer in the field, with the creation and implementation of large-scale, strategic, and customized positive education programs or positive psychology interventions (Green, 2014). This interest was born out of the first global large-scale strategic Positive Education Program launched at Geelong Grammar School in 2008 in Australia with the support of Professor Martin Seligman and his colleagues. Since that time, other Australian schools have followed suit. In addition, Australia has played host to the First and Second "Positive Psychology in Education" Symposiums hosted by the Coaching Psychology Unit, University of Sydney in 2009 and 2011, and the First Australian Positive Education Conference hosted by Knox Grammar in 2011. Since then, a range of other positive education conferences has been hosted across Australia.

Positive education ideally should be applied strategically across whole-school settings and embedded implicitly into the culture, as no two school systems would implement a positive education process identically (Clonan, et al., 2004). However, at this point in time, it is most readily seen in the application of positive psychology interventions (PPIs) in school settings. PPIs can be defined as initiatives that aim to "cultivate positive feelings, positive behaviors, or positive cognitions" (Sin \& Lyubormisky, 2009, p. 467). Such PPIs can take the form of either singlecomponent PPIs (that focus on single key psychological constructs, e.g., gratitude), or multicomponent PPIs (that focus on helping students develop skills in several psychological domains) (Proctor, Maltby, \& Linley, 2011). "Strengths Gym" is an example of a multi-component PPI that is aimed at developing character strengths through various exercises, in-class activities, discussions, and homework (Proctor, Tsukayama, et al., 2011).

Another recent development in the field of positive education is the increasing focus on building school staff's capability to deliver wellbeing programs within schools. In Australia, schools are embracing whole-school approaches to positive education, and teachers are undergoing extensive training in order to roll out such wellbeing programs to students, developing their own wellbeing and interpersonal skills in the process (Green, 2014). However, the research examining the effects of positive education programs on teachers is relatively scant. Recent research from Geelong Grammar School provides some qualitative data on the perceived benefits of a positive education program (Norrish, 2015). While it is hoped that both staff and students are able to experience the wellbeing effects created by positive education programs, further research is required in this area. 


\section{Coaching in schools}

Whilst coaching has been popular in organizational settings since the early 1990's, more recently it is being considered and adopted in educational settings (van Nieuwerburgh, 2012). Coaching psychology has been defined as the systematic application of behavioral science to the enhancement of life experience, work performance and wellbeing of individuals, groups and organizations (Stober \& Grant, 2006). In coaching, the coach facilitates enhancement of the client's goal attainment and wellbeing, and fosters self-directed learning and personal growth (Green, Grant, \& Rynsaardt, 2007).

The growing interest in coaching in education is evidenced by the growing body of research suggesting that coaching is an effective intervention for students and staff within educational contexts. Coaching interventions conducted with students may often extend beyond a focus on academic performance to a focus on students' life goals, their enhanced wellbeing and improved mental health. In a study utilizing a randomized wait-list control group with female senior high school students, Green et al. (2007) found that students in the coaching program experienced a significant increase in levels of cognitive hardiness and hope. Participants also experienced a significant decrease in levels of depression. The current study builds on Green et al., (2007) by adding measures of goal commitment and goal attainment to explore participants' own goal progress and achievement. The current study also examined the impact of an evidence-based coaching program as part of a positive education program at the school, as opposed to a standalone intervention.

A study comparing the effects of coaching programs and PPIs on 73 male and female adolescents aged 15 to 17 years in Australian high schools found that participation in the PPI program led to increases in mental wellbeing up to the nine-month follow-up, compared with the coaching program (Green, Norrish, Vella-Brodrick, \& Grant, 2014). Participating in the coaching group was associated with increased academic goal striving compared to the PPI and control group, again up to a nine-month follow-up (Green et al., 2014).

Evidence-based coaching has also demonstrated results with primary school students. A strengths-based coaching program undertaken by 38 year 5 (mean age 10;7) male students was associated with significant increases in self-reported levels of engagement and hope (Madden, Green, \& Grant, 2011). While such coaching programs may be considered as potential mental health interventions, further research is required. The current study adds to this literature by providing more evidence for the benefits of a coaching initiative as part of a broader positive education program.

Specifically, the aim of the coaching trial was: firstly, to provide an evidence-based coaching intervention for the senior students as part of the Positive Education Program to enhance wellbeing, and secondly, to enhance academic outcomes for students.

The study used a peer coaching model in order to maximize cost and time effectiveness. While not as effective as one-on-one coaching, peer coaching has been found to be an effective strategy in delivering coaching interventions (Green, Oades, \& Grant, 2006; Spence \& Grant, 2005) where individual coaching is not applicable due to cost or time restrictions.

\section{Aims of the research}

The main aim of the coaching trial was to enhance mental wellbeing, cognitive hardiness, and personal and academic goal strivings (motivation and success) in students, given the increasing awareness that schools should aim to not only improve academic outcomes but wellbeing outcomes (Seligman, 2009). In addition, and as noted in the introduction, there is a need for 
further research both on positive psychology applications in schools, of which coaching is one approach, and more research on coaching in schools generally.

The Positive Education Program in the school was launched in 2011 to replace an existing Life Education Program. Initially, the program for each of the five year levels was developed under categories that aligned with Seligman's (2011) PERMA model of wellbeing: Positive Purpose/Positive Relationships/Positive Identity/Positive Relationships. These areas were also similar to those used by Geelong Grammar School for their Positive Education Program.

These categories were used until 2015, when, after evaluating the program, the school moved to adopt five positive psychology constructs (already utilized in the program which began in 2011) as the main focus of the program. The constructs were: character strengths and virtues (Peterson \& Seligman, 2004), gratitude (Emmons \& McCullough, 2003), mindfulness (Burke, 2010), flow (Csikszentmihalyi, 1990) and savoring (Bryant, 2003). These constructs are evidencebased positive psychology constructs with considerable research behind each of them. The school adopted these particular five constructs because: they are evidence-based; they were already in the program from the beginning but required greater a more in-depth understanding; they complement the school ethos (hope, justice, love and compassion); and they are constructs that can be explicitly taught to be applied in a practical way by students. In addition, researchers are calling for more empirical evidence on multiple constructs and whole school programs (van Nieuwerburgh, 2012; Waters, 2011; Norrish \& Vella-Broderick, 2009).

The specific aims of the trial were: increased levels of wellbeing; increased levels of hardiness; decreased levels of depression, stress and anxiety; increased goal striving (academic \& personal); increased autonomous motivation; and increased academic achievement. These measures were chosen because the school viewed the enhancement of wellbeing and resilience, and the enhancement of academic results as being the two main aims of the coaching program.

\section{Participants}

This study took place in an all-girls' Catholic high school in Queensland, Australia. The participants were 37 senior high school students (year 11, mean age 15;9) who were randomly selected to participate in the trial. Given coaching is designed for a "normal, non-clinical population" (Grant, 2003), a mental health assessment was conducted prior to the study to ensure that students did not present any clinical issues. Their scores on the Depression, Anxiety and Stress Scale (DASS, Lovibond \& Lovibond, 1995) all fell within the normal or low end of mild range of psychopathology.

Prior to the study commencing, students were given information about the trial and informed that a number of students would be randomly selected to participate in the trial. School management agreed to run a pilot trial with one-third of the year 11 students. Year 11 comprised 134 students grouped into six home-room groups. Ten students from each room were randomly selected. The random selection process involved extracting the names of all year 11 students from the school management system and importing them into a Microsoft Excel file. The random generator feature within Microsoft Excel was used to create a random sample. The first ten students from each home-room list were then selected to take part in the study.

The 60 selected students' parents were approached for permission to participate in the study. Parental permission was obtained for 37 students (61.67\%). The 37 participants for whom parental permission was obtained comprised the intervention group and were randomly assigned to four groups (one teacher and one college psychologist ran two groups each). Preintervention responses were completed by 35 students. Of these 35, only 25 completed the postintervention measures ( $71 \%$ response rate). These non-respondents in the post-condition were 
not included in the total analysis, reducing the study sample size to 25. Despite the small sample size, the results were considered sufficiently positive to consider a wider rollout of the coaching program in the following session.

\section{Procedure}

The Positive Education Program for all year levels (years 7-12) comprised timetabled classes (of approximately 11 hours per term for years $8-10$, and 6 hours per term for students in years 11 and 12) where a variety of positive psychology concepts were explicitly taught to students. The school identified two important trajectory points where interventions could be most effective:

1) Transition to high school - year 8 (12 - 13 years old)

2) Transition to senior school - year 11 (15 - 16 years old).

The Positive Education Program had already catered for the first transition in year 8 by emphasizing performance psychology as a particular focus of the Positive Education Program for year 8 students. In addition, senior teaching staff in the school perceived that students transitioning from year 10 to senior school experienced difficulties, an area that has been previously identified in the literature (Shoshani \& Slone, 2013). These included anxiety, stress, inappropriate subject choices, unrealistic expectations, limited understanding of individual strengths, and inability to meet the requirement for the increased workload. Hence, facilitating students' transition to year 11 was identified as a key focus of the study.

The selection process was completed at the end of the year prior to the program commencing. The program commenced the following year and lasted for two school terms, approximately half of the school year. This was judged by the school as a significant trajectory point for the trial, as these students had just finished the Queensland Studies Authority compulsory Senior Education \& Training (SET) Plans in year 10, where students choose subjects and plan career aspirations to be pursued in the senior school years. Staff at the school had observed that many students at this time (aged approximately 15) were not confident deciding on career options, and were still developing their strengths and capabilities. This observation has also been identified in the scientific literature whereby "academic self-concept" has been shown to be a significant predictor of subject selection (Craven \& Marsh, 2008). The school considered that a coaching intervention at this point would allow students to develop skills in goal setting, striving and attainment, giving them confidence in decision-making skills and goal achievement.

Students were provided with a Student Life-Coaching Manual for the ten weeks of the trial, which set out the content to be covered in the ten sessions. The two teachers and one college psychologist compiled a Teacher Life-Coaching Manual (from their life coaching training) to supplement the work in the student manual. The student manual was a combination of information, activities and exercises for students to complete, and also contained segments used for inspiration and motivation.

The coaching program was advertised through an information session held at a whole-school year-level assembly, with all girls in attendance. Additionally, the program was advertised in the school newsletter, and a number of emails were sent to year 11 students. The 60 girls who were randomly selected were provided with a Participant Information Sheet and a consent form for both themselves and their parents to sign if they wished to participate in the trial.

Participants were randomly assigned to one of four groups (three groups of nine students and one group of ten students) with one facilitator - either a teacher or the psychologist conducting the trial. Participants completed a ten-session coaching program.

Teachers were trained as coach/facilitators to support the student coaches, and to ensure that ongoing coaching training could be provided. The teacher training comprised a two-day 
workshop in evidence-based coaching provided by an expert consultant. Fifteen teachers attended the training. The teachers were trained in the theories of coaching psychology and practices of evidence-based coaching. A teacher-training manual was provided for these two days, and Table 1 below outlines the key topics covered in training.

Table 1. Coaching manual topics (weeks 1 to 10)

\begin{tabular}{ll}
\hline Week & Topic \\
\hline Weeks 1 to 3: & $\begin{array}{l}\text { Students were taught the principles of coaching, covering a range of topics, in } \\
\text { particular, the GROW model. }\end{array}$ \\
Weeks 4 to 9: & $\begin{array}{l}\text { Co-coaching sessions were held where students worked with a partner and } \\
\text { applied the GROW model. }\end{array}$ \\
Week 10: & \begin{tabular}{l} 
Students took part in celebrating the end of the trial. \\
\hline
\end{tabular}
\end{tabular}

\subsection{The coaching program}

The coaching program consisted of ten group-coaching sessions with the allocated teacher-coach, conducted over a period of two school terms (22 weeks including a two-week term break). The school has a six-day lesson cycle, so the coaching comprised one lesson every six-day cycle. The coaching program involved participants holistically examining aspects of their lives and identifying two goals that they wished to be coached on: one academic and one personal. The program was based on a solution-focused cognitive-behavioral framework that was utilized in three previous randomized, controlled studies on evidence-based coaching (Green et al., 2006; Spence \& Grant, 2005; Green, Grant \& Rynsaardt, 2007).

Each coaching session involved the setting of session goals, followed by a brief discussion of issues pertaining to the students' lives. Each coaching session commenced with a typical mindfulness exercise (asking students to focus on the present moment, thoughts and sensations without judgment) to assist with improving attentional capacity and inducing feelings of calm (Campion \& Rocco, 2009). This addition to the coaching program was included, based on previous research that showed that mindfulness practice could enhance coaching outcomes (Spence, Cavanagh, \& Grant, 2008). This was followed by a group check-in for an update on each student's goal progress. Students shared ideas and strategies for achieving their goals. After this brief check-in, students received information about coaching topics (see Table 1 above). An aim of the coaching program was to raise the students' personal awareness of their current situation, academically and personally.

The first part of the trial (weeks 1 to 3) was centered on students developing skills in goal setting and coaching, and formulating SMART (Specific, Measurable, Achievable, Realistic, Time-bound) goals to strive towards during the coaching program. During the second part of the trial (weeks 4 to 9), participants worked in pairs and co-coached each other using the GROW (Goals, Reality, Options, Wrap-up) Model (Whitmore, 2003) to support successful goal striving. They had time to assist each other to identify personal resources that could be utilized in moving towards their goals, and to develop self-generated solutions and specific action steps. Working in pairs, the participants worked systemically through the self-regulation cycle of setting goals and developing action plans, as well as monitoring and evaluating progress. During these sessions, the teacher acted as a consultant with each group of pairs, and offered constructive feedback as they continued to develop their coaching skills. The final session (week 10) was one of reflection, celebration and looking forward. 
The teacher and psychologist conducting the trial met to organize the ten-session trial, and set regular meeting times to assess the progress of the trial and share strategies for keeping students engaged. The role of the teacher and psychologist in the trial was to train the students in the GROW model, and then oversee the co-coaching process with the participants. As part of this process, they also role-modeled the coaching process.

\subsection{Experimental design}

A within-subjects design was utilized (with no control group). Wellbeing, hope and cognitive hardiness were assessed at pre-intervention and post-intervention. Students were asked to identify their personal and academic goals, and goal commitment measures were taken. Students completed a survey before the coaching program started and again after the program ended. Students completed an online survey the week before the trial began and completed the survey again at the end of the program.

\subsection{Wellbeing measures}

A range of wellbeing measures was selected to examine the impact of the coaching program on the students' wellbeing. The following measures were used pre- and post-intervention to evaluate the impact of the coaching intervention:

Warwick-Edinburgh Mental Well Being Scale (WEMWBS). WEMWBS is a measure of mental wellbeing focusing entirely on positive aspects of mental health (Tennant, et al., 2007). It is a short and psychometrically robust scale and can be used as a tool for monitoring mental wellbeing at a population level or organizational level. It is used for both adults and children aged 13 and above. The WEMWBS is useful for evaluating mental health promotion initiatives.

Trait Hope Scale. This scale measures the traits of agency and pathways that indicate high levels of hope in individuals. The Trait Hope Scale (Snyder et al., 1991) is a 12-item measure of the two dimensions of hope, ranging from 1 (definitely false) to 4 (definitely true). It consists of four agency items (i.e., items that tap the belief in one's ability to initiate and maintain movement towards goals), four pathways items (i.e., items that tap the ability to conceptualize routes to a goal), and four filler items. A total score is used as a measurement of the global concept of hope and is calculated as the sum of the eight agency and pathways items (range $=8$ to 32). Test retest reliabilities for the Trait Hope Scale suggest temporal stability (.83 over a three-week interval, .73 over an eight-week period) (Snyder et al., 1991). Alpha coefficients for the two subscales are acceptable (agency $=.71$ to .77 ; pathway $=.63$ to .80 ) (Snyder et al., 1991). The alpha coefficients in this study were .79 for agency and .80 for pathways. This instrument demonstrates both internal and temporal reliability, with two separate and yet related factors, as well as an overarching hope factor (Babyak, Snyder \& Yoshinobu, 1993). Several studies have confirmed its convergent and discriminant validity (Snyder, 2000).

Cognitive Hardiness Scale (CHS). The CHS measures hardiness. Hardiness may explain differences in mood states among groups of individuals who are subjected to stress and may have a buffering effect against stressful events (Kobasa, 1979). Hardiness is composed of three components: commitment, the ability to be deeply involved in or committed to the activities in one's life; control, the belief that one can control or influence the events experienced in life; and challenge, viewing the changes in one's life as exciting rather than as threatening (Kobasa, Maddi, Puccetti, \& Zola, 1985).

Depression Anxiety Stress Scale (DASS). This scale measures the negative emotional states of depression, anxiety and stress. The DASS is a set of three self-report scales designed to measure the negative emotional states of depression, anxiety and stress (Lovibond \& Lovibond, 1995). The 
DASS has been shown to have high internal consistency and to yield meaningful discriminations in a variety of settings. Each of the three DASSs contains 14 items, divided into subscales of two to five items with similar content. Subjects are asked to use 4-point severity/frequency scales to rate the extent to which they have experienced each state over the past week. Scores for depression, anxiety and stress are calculated by summing the scores for the relevant items.

Goal striving and goal commitment. Students were asked to set a personal goal and an academic goal during the coaching intervention. For each of these goals, they completed a questionnaire where they were asked a series of four questions (5-point Likert scale) that identified the degree of autonomous motivation they applied to each goal. Self-determination theory (SDT) (Deci \& Ryan, 1985) is a theory of human motivation that has been extensively studied in the psychological literature. It involves a set of related theories that define and explain human behaviour by defining different types of motivation that an individual may engage in to complete a task or set of activities. SDT provides an understanding of what motivates individuals and provides an insight into how different types of motivation may impact employee engagement. Participants were asked to rate the extent to which they were motivated to achieve a goal (from "1 - not at all for this reason" to " 5 - entirely for this reason") based on four statements derived from self-determination theory (Deci \& Ryan, 1985). The four statements addressed four different motivation states as defined by SDT: intrinsic motivation ("Striving because of the fun and enjoyment which the goal provides you. While there may be many good reasons for the goal, the primary reason is simply your interest in the experience itself"). The remaining three statements are based on three extrinsic motivation states; introjected regulation ("Striving, because you would feel ashamed, guilty or anxious if you didn't. Rather than striving just because someone else thinks you ought to, you feel that you ought to strive for that something."); integrated regulation ("Striving because you really believe that it's an important goal to have. Although this goal may once have been taught to you by others, now you endorse it freely and value it wholeheartedly."); and external regulation ("Striving because somebody else wants you to or thinks you ought to, or because you'll get something from somebody if you do. That is, you probably wouldn't strive for this if you didn't get some kind of reward, praise, or approval for it."). This approach to goal attainment scaling (Sheldon \& Elliot, 1998) has been used in prior coaching outcome studies (e.g., Green et al., 2006; for a compressive discussion of the use of different approaches for the measurement of goal attainment in coaching, see Spence, 2007).

Students were also asked to rate their success in striving towards each academic and personal goal, and to rate their commitment to each academic and personal goal. Students' goal striving was measured by the question "In the last ten weeks, how successful have you been in attaining your strivings?" Participants were then asked to provide a percentage estimate in $20 \%$ increments (totalling five e.g., "0 - 20\% successful" up to "81-100\% successful"). Students were then asked to rate "How committed do you feel towards this goal?" in order to measure their perception of success and commitment for achieving the goal. The responses for this question comprised a 5point Likert rating scale for this question ranging from "not at all committed" to "extremely committed".

\section{Results}

A paired-sample t-test was conducted to measure differences between the means for the preintervention and post-intervention groups. A paired sample t-test is used to determine whether there is a significant difference between the average values of the same measurement made under two different conditions (Minium, 1978). The null hypothesis for a paired sample t-test is that the variance of the variable means is zero. Results of the analysis for each of the wellbeing 
measures appear below. Table 2 below outlines the results for all of the wellbeing measures comparing the pre and post measures in the experimental group.

Table 2. Paired samples statistics for all wellbeing measures scores $(n=25)$

\begin{tabular}{|c|c|c|c|c|}
\hline & Mean & Std. Deviation & Std. Error Mean & Sig. (2-tailed) \\
\hline \multicolumn{5}{|l|}{$\underline{\mathrm{DASS}}$} \\
\hline \multicolumn{5}{|c|}{ Depression subscale } \\
\hline Pre-test & 10.24 & 9.35 & 1.87 & \\
\hline Post-test & 7.84 & 7.37 & 1.47 & .06 \\
\hline \multicolumn{5}{|c|}{$\underline{\text { Anxiety subscale }}$} \\
\hline Pre-test & 8.16 & 6.32 & 1.26 & \\
\hline Post-test & 8.00 & 6.66 & 1.33 & .89 \\
\hline \multicolumn{5}{|c|}{$\underline{\text { Stress subscale }}$} \\
\hline Pre-test & 15.04 & 6.69 & 1.34 & \\
\hline Post-test & 13.52 & 6.20 & 1.24 & .22 \\
\hline \multicolumn{5}{|c|}{ Hope Trait Scale } \\
\hline \multicolumn{5}{|c|}{$\underline{\text { Pathway subscale }}$} \\
\hline Pre-test & 24.88 & 4.25 & .85 & \\
\hline Post-test & 24.96 & 3.91 & .78 & .88 \\
\hline \multicolumn{5}{|c|}{ Agency subscale } \\
\hline Pre-test & 24.20 & 4.78 & .96 & \\
\hline Post-test & 25.32 & 3.72 & .74 & .11 \\
\hline \multicolumn{5}{|c|}{ WEMWBS } \\
\hline Pre-test & 3.59 & .524 & .10 & \\
\hline Post-test & 3.75 & .55 & .11 & $.05^{*}$ \\
\hline \multicolumn{5}{|c|}{ Cognitive Hardiness Scale } \\
\hline Pre-test & 3.43 & .48 & .10 & \\
\hline Post-test & 3.56 & .40 & .08 & $.03^{*}$ \\
\hline
\end{tabular}

${ }^{*} p=0.05$

DASS Questionnaire (Depression, Anxiety $\mathcal{E}$ Stress Subscales). A reduction in DASS scores represents an improvement on each of the scales. All pre-test mean scores were at the low end of the mild range: Depression subscale (mild range $=10-13)(m=10.24)$; Anxiety subscale (mild range $=8-9)(m=8.16)$; Stress subscale (mild range $=15-18)(m=15.04)$. Post-test scores showed a trend towards improvement, although these were not significant changes: Depression subscale (normal range $=0-9)(m=7.84, p=.06)$; Anxiety subscale $(m=8.00, p=.89)$; Stress subscale (normal range $=0-14)(m=13.52, p=.22)$. The scores for the Depression subscale were approaching significance in a positive direction.

HTS. Table 2 above also shows the means, standard deviation and standard error means for the HTS subscales. Either the separate subscales or the total score can be used. In this study, the subscales were used to investigate any changes in the two different aspects of HTS (pathway and agency). There were slight increases in the post-test scores for both Pathway $(m=24.96)$ and 
Agency $(m=25.32)$, however, neither of these was significant, as shown (Pathway: $p=.88$, Agency: $\mathrm{p}=.11)$.

WEMWBS. There was a significant difference $(p=0.05)$ between the pre-intervention $(m=$ 3.59 ) and post-intervention ( $m=3.75)$ scores on the WEMWBS (measuring mental wellbeing) such that students' scores showed an increase in mental wellbeing after the coaching intervention.

CHS. Students' scores on the CHS increased (i.e., students reported higher levels of cognitive hardiness) after the coaching intervention. Only the average score for the CHS was calculated. There was a significant difference between the pre-intervention $(m=3.43)$ and post-intervention ( $m=3.56$ ) scores on the CHS (which measures students' commitment, their perception of changes as challenging rather than threatening, and a greater belief in their sense of control over their lives) $(p=0.03)$.

Goal Striving and Goal Commitment. The results for this analysis appear below. Table 3 below shows the means, standard deviations, and standard error means for the pre- and post-, personal and academic goal striving, and goal commitment scores.

Table 3. Paired samples statistics - students' goal striving and commitment scores

\begin{tabular}{lcccc}
\hline Measure & Mean & N & Std. Dev. & Sig. \\
\hline Personal Goals & & & & \\
Pre-Personal Goal Striving & 3.00 & 24 & 1.25 & \\
Post-Personal Goal Striving & 4.33 & 24 & .82 & $.00^{*}$ \\
Pre-Personal Goal Commitment & 4.20 & 25 & 1.08 & \\
Post-Personal Goal Commitment & 4.36 & 25 & .99 & .52 \\
Academic Goals & & & & \\
Pre-Academic Goal Striving & 3.68 & 25 & 1.22 & .37 \\
Post-Academic Goal Striving & 3.92 & 25 & .95 & .26 \\
Pre-Academic Goal Commitment & 4.40 & 25 & .91 & \\
Post-Academic Goal Commitment & 4.20 & 25 & .76 & \\
\hline
\end{tabular}
${ }^{*} p=0.05$

There was a significant increase in students' perceptions of how successfully they achieved their strivings towards their personal goal. Students indicated that they more successfully achieved their personal goals after the coaching intervention. The other three measures: personal goal commitment, academic goal striving, and academic goal commitment showed a trend towards increased success and commitment in the post-intervention scores, but did not achieve significance.

\section{Discussion}

The evidence-based coaching intervention appears to have had a positive impact on some aspects of students' mental health and wellbeing. Specifically, wellbeing scores after the coaching intervention were significantly higher than wellbeing scores before the coaching intervention. However, two aspects of the study require these results to be viewed with some caution. First, the sample size of the intervention group was small, with only 25 students. Second, no control group measures were taken, resulting in an inability to make any comparisons between groups.

There was no significant difference in students' pre- and post-intervention depression, anxiety and stress scores. Students' scores on the DASS depression and anxiety subscales were 
in the mild range for both pre- and post-intervention, while scores for the DASS stress subscales were in the normal range. The small sample size for this study may have impacted the likelihood of finding a significant difference on these scales. Participants were screened for exclusion based on mental health issues at the beginning of the program (with none being excluded). The transition from middle to high school can be stressful and challenging and is referred to in the literature as "one of the defining parameters of development in the second decade of life" (Barber \& Olsen, 2004, p. 3). The fact that students in the coaching program did not experience an increase in stress shows a positive impact. In addition, for the DASS stress subscales then, there may have been a floor effect, i.e., a limitation reached in how far these scores could be reduced by the intervention.

Students' post-intervention overall scores in cognitive hardiness were significantly higher than their pre-intervention scores, demonstrating an increase in students' commitment, their perception of changes as challenging rather than threatening, and a greater belief in their sense of control over their lives.

Students indicated that they felt they more successfully achieved their personal goals after the coaching intervention (personal goal striving). While there was a trend towards improvement on students' scores for academic and personal goal commitment, and academic goal striving, these were not significant. Students indicated that they did not feel more committed to either their personal or academic goals, nor did they feel they more successfully achieved their academic goals after the coaching intervention. However, the lack of significant results may be impacted by the small sample size in this study.

The school considered the results of the pilot study at the conclusion of the trial in 2013. In examining the promising results reflected in the pilot study data, the college principal and the leadership team decided to extend the program to the whole year 11 cohort. The college wanted to provide all year 11 students with the opportunity to experience coaching, as this approach aligned with work already being done with students, such as goal setting, and the positive education program, based on positive psychology. Consequently, the school decided to extend the coaching intervention to the entire year 11 cohort in 2014, with 15 trained teacher-coaches delivering the program.

Students also completed an online evaluation survey at the end of the trial and provided valuable feedback as to the implementation of this coaching program. Numerical and anecdotal comments provided useful feedback for improvement. These included moving the timing of the coaching sessions so that they did not occur near exam periods, and shortening the coaching program, as some respondents was considered it too long.

The feedback from students was generally positive. Anecdotally, all students who took part in the coaching program articulated that they learnt something from the program. The majority indicated that they would use what they learnt beyond the program, indicating valuable transferability of skills, especially at such a critical and stressful time in an adolescent's life.

A major limitation of this study is that while all students in the year 11 cohort took part in the broader positive education program, only those students who took part in the coaching program completed the various measures, and subsequently, are reported here. This was a decision made by the school in terms of piloting the program prior to consideration of its full uptake. In addition, the costs and resources associated with administering the tests to all year 11 students for a pilot program need to be taken into account. Future research could include feedback from students who were not included in the coaching program, but who took part only in the positive education program. Another limitation of the study was that longer-term followup measures were not taken, making it impossible to assess whether any benefits were sustained over time. 
After evaluating the trial, a number of changes were made for the 2014 program. Minor changes were made to the student-coaching manual. The coaching program was extended to include a variety of activities in each session to sustain student engagement (e.g., mindfulness, resource sheets, You-Tube clips, "whip around" sessions, affirmations). The coaching program was shortened to consist of eight rather than ten sessions.

Sample comments from students followed up via a personal email from one of the teachers, one month after the trial, indicated how the students were progressing towards achievement of their goals after the program. Students felt that their goals were going well, and that their planning and organizing skills were improved. Some sample comments included:

1) "My goals are both still pretty well on track and I have been using many of the tips you taught us."

2) "My goals are going quite well actually, I am receiving good marks in all my subjects and I still continue to improve, and in relation to my personal goal I am currently in the highest point in my hockey season and from the results we've received recently, we have a definite position in the semifinals coming up in a few weeks."

3) "My goals are going great this term and I have my planning and organisation all sorted out."

4) "I've become so organised in my homework and planning ahead for my school work that I've had to organise my brother study (sic) for his Uni work! Thank you for 'checking in' In the long term I've developed good habits."

5) "Thank you for checking in with us about how our goals are progressing."

6) "I am very happy with how I am going and I found that my semester results after last term met the goals that I set for myself, particularly in English where I exceeded my goal. I am still putting in place the goal-setting tips that you taught us and I am grateful for the opportunity to participate in the Life Coaching Program."

7) "My personal and academic goals have been going well this term and I really enjoyed the life coaching."

A teacher not involved in the trial observed a group co-coaching (towards the end of the trial) using the SMART goal process and commented in her reflection:

"The coaching technique that students used with each other was intuitive and seamless as they progressed through the questions and stages of coaching each other. They did not have to rely on the question sheet at this time and seemed genuinely engaged with the process and knew the questions without having to rely on the handout. They were highly motivated when challenging each other with their commitments and established whether the strategies were working in order to meet the SMART goal they had set for each other. When communicating with each other the students used deep and active listening techniques and seemed to follow the 80/20 rule well."

The results indicated that the trial was successful and that the program increased personal striving towards goals and had a positive effect on student wellbeing. Given that senior high school (the start of year 11 in Australia) is a time when there is a tendency towards increased stress due to transitioning into the senior school, the fact that students in this trial did not show increased stress is a significant finding. Further study specifically examining this question would be valuable in developing a program to assist students in making the transition from middle school to senior school. It would be valuable, for example, to compare the stress levels of students in an intervention group with those in a control group during such a transition.

\section{Conclusion}


This study provides further evidence of the impact on students' mental health and wellbeing of implementing an evidence-based coaching program within a high school setting. Further, it provides practical information for practitioners wanting to conduct similar trials in educational institutions. Finally, the study demonstrates the value of integrating evidence-based coaching programs within broader Positive Education Programs at schools to fully embed the complementary methods and skills in each area. In this study, the school found that the coaching program was able to support and build on the five constructs of the Positive Education Program (strengths, gratitude, mindfulness, savoring, flow), indicating the capacity-building outcomes of this integrated program. Ongoing research that integrates positive psychology interventions and evidence-based coaching would be valuable to further ascertain the cumulative and individual impact of programs with these two approaches

It is worthy to note that this coaching program was conducted in 2013. After consideration of the promising results of the program, despite the small number of participants, the coaching program was offered, with some minor changes, to the entire year 11 cohort of students in 2014 (approximately 150 students). As well as 2014, the coaching program has continued (in 2015 and 2016) to be offered to the entire cohort of year 11 students (approximately 150 students each year). The coaching program is successfully providing students in transition to senior school valuable goal setting, striving, and achievement skills. An initiative that grew out of the coaching program is the coaching buddy program. This operated in 2015 and 2016, and occurs for four sessions in terms 3 and 4, where all year 11 students trained in coaching work with all Year 7 students on goal attainment. The benefits of this initiative are twofold. First, the year 11 students have an opportunity to put their coaching skills into action by working with year 7 students. Second, the year 7 students have the opportunity to learn about coaching and the GROW model and to work on their own goals.

\section{Authors}

Aylin Dulagil

The Positivity Institute

adulagil@bigpond.net.au

L. Suzy Green

The Positivity Institute

Madonna Ahern

Mt St Michael's College

Publishing Timeline

Received 4 December 2015

Accepted 2 May 2016

Published 14 October 2016

\section{References}

Babyak, M. A., Snyder, C. R., \& Yoshinobu, L. (1993). Psychometric properties of the Hope Scale: A confirmatory factor analysis. Journal of Research in Personality, 27(2), 154-169. http://dx.doi.org/10.1006/jrpe.1993.1011

Barber, B. K., \& Olsen, J. A. (2004). Assessing the transitions to middle and high school. Journal of Adolescent Research, 19(1), 3-30. http://dx.doi.org/10.1177/0743558403258113

Bryant, F. (2003). Savoring Beliefs Inventory (SBI): A scale for measuring beliefs about savouring. Journal of Mental Health, 12(2), 175-196. 
Burke, C. A. (2010). Mindfulness-based approaches with children and adolescents: A preliminary review of current research in an emergent field. Journal of Child and Family Studies, 19(2), 133-144.

Cain, G., \& Carnellor, Y. (2008). 'Roots of empathy': A research study on its impact on teachers in Western Australia. Journal of Student Wellbeing, 2(1), 52-73.

Campion, J., \& Rocco, S. (2009). Minding the mind: The effects and potential of a school-based meditation programme for mental health promotion. Advances in School Mental Health Promotion, 2(1), 47-55. http://dx.doi.org/10.1080/1754730X.2009.9715697

Clonan, S. M., Chafouleas, S. M., McDougal, J. L., \& Riley-Tillman, T. C. (2004). Positive psychology goes to school: Are we there yet? Psychology in the Schools, 41(1), 101-110. http://dx.doi.org/10.1002/pits.10142

Craven, R. G., \& Marsh, H. W. (2008). The centrality of the self-concept construct for psychological wellbeing and unlocking human potential: Implications for child and educational psychologists. Educational and Child Psychology, 25(2), 104-118.

Csikszentmihalyi, M. (1990). Flow: The psychology of optimal performance. New York, NY: Cambridge University Press.

Deci, E. L., \& Ryan, R. M. (1985). The general causality orientations scale: Self-determination in personality. Journal of Research in Personality, 19(2), 109-134.

Durlak, J. A., Weissberg, R. P., Dymnicki, A. B., Taylor, R. D., \& Schellinger, K. B. (2011). The impact of enhancing students' social and emotional learning: A meta-analysis of school-based universal interventions. Child Development, 82(1), 405-432. http://dx.doi.org/10.1111/j.1467-8624.2010.01564.x

Emmons, R. A., \& McCullough, M. E. (2003). Counting blessings versus burdens: An experimental investigation of gratitude and subjective well-being in daily life. Journal of Personality and Social Psychology, 84(2), 377.

Gill, S. (2009). Monitoring and promoting wellbeing in education principles and possible approaches to child wellbeing indicators. Brighton, United Kingdom: Education for Wellbeing Europe Consortium.

Gilman, R., Huebner, E. S. \& Furlong, M. J., (Eds.). (2009). Handbook of positive psychology in schools. New York, NY: Routledge.

Grant, A. M. (2003). The impact of life coaching on goal attainment, metacognition and mental health. Social Behavior and Personality, 31(3), 253-264. http://dx.doi.org/10.2224/sbp.2003.31.3.253

Grant, A., \& Cavanagh, M. (2007). Evidence-based coaching: Flourishing or languishing? Australian Psychologist, 42(4), 239-254. http://dx.doi.org/10.1080/00050060701648175

Green, L. S. (2014). Positive education: An Australian perspective. In M. J. Furlong, R. Gilman \& E. S. Huebner (Eds.), Handbook of positive psychology in schools (2nd ed.) (pp. 401-415). New York, NY: Routledge.

Green, L. S., Grant, A. M., \& Rynsaardt, J. (2007). Evidence-based life coaching for senior high school students: Building hardiness and hope. International Coaching Psychology Review, 2(1), 24-32.

Green, L. S., Norrish, J. M., Vella-Brodrick, D. A., \& Grant, A. M. (2014). Enhancing wellbeing and goal striving in senior high school students: Comparing evidence-based coaching and positive psychology interventions. http://www.instituteofcoaching.org/resources/enhancing-well-being-andgoal-striving-senior-high-school-students-comparing-evidence

Green, L. S., Oades, L. G., \& Grant, A. M. (2006). Cognitive-behavioral, solution-focused life coaching: Enhancing goal striving, wellbeing, and hope. The Journal of Positive Psychology, 1(3), 142-149. http://dx.doi.org/10.1080/17439760600619849

Green, L. S., Oades, L. G., \& Robinson, P. (2011). Positive education: Creating flourishing students, staff and schools. InPsych: The Bulletin of the Australian Psychological Society Ltd, 33(2), 16-18.

Huitt, W. (2010). Analyzing paradigms used in education and schooling. Educational psychology interactive. Valdosta, GA: Valdosta State University.

Huppert, F. A., \& Johnson, D. M. (2010). A controlled trial of mindfulness training in schools: The importance of practice for an impact on well-being. Journal of Positive Psychology, 5(4), 264-274. http://dx.doi.org/10.1080/17439761003794148

Kobasa, S. C. (1979). Stressful life event, personality and health: An inquiry into hardiness. Journal of Personality and Social Psychology, 37(1), 1-11. http://dx.doi.org/10.1037/0022-3514.37.1.1 
Kobasa, S. C., Maddi, S. R., Puccetti, M. C., \& Zola, M. A. (1985). Effectiveness of hardiness, exercise and social support as resources against illness. Journal of Psychosomatic Research, 29(5), 525-533. http://dx.doi.org/10.1016/0022-3999(85)90086-8

Lovibond, P. F. \& Lovibond. S. H. (1995). The structure of negative emotional states: Comparison of the Depression Anxiety Stress Scales (DASS) with the Beck Depression and Anxiety Inventories. Behaviour Research and Therapy, 33(3), 335-343. http://dx.doi.org/10.1016/0005-7967(94)00075-U

Madden, W., Green, L. S., \& Grant, A. M. (2011). A pilot study evaluating strengths-based coaching for primary school students: Enhancing engagement and hope. International Coaching Psychology Review, $6(1), 71-83$.

McGrath, H. (2009, May). An evidence-based positive psychology approach to student wellbeing. Paper presented at the First Australian Positive Psychology in Education Symposium, Sydney, Australia.

Minium, E. W. (1978). Statistical reasoning in psychology and education. New York, NY: John Wiley \& Sons.

New South Wales Department of Education and Communities. (2015). The Wellbeing Framework for Schools. https://www.det.nsw.edu.au/wellbeing/about/16531 Wellbeing-Framework-forschools Acessible.pdf

Norrish, J., \& Vella-Broderick, D. (2009). Positive psychology and adolescents: Where are we now? Where to from here? Australian Psychologist, 44(4), 270-278.

http://dx.doi.org/10.1080/00050060902914103

Norrish, J. (2015). Positive Education: The Geelong Grammar School Journey. Oxford, England: Oxford University Press.

Peterson, C., \& Seligman, M. (2004). Character strengths and virtues: A handbook and classification. New York, NY: Oxford University Press.

Proctor, C., Maltby, J., \& Linley, P. A. (2011). Strengths use as a predictor of wellbeing and health-related quality of life. Journal of Happiness Studies, 12(1), 153-169. http://dx.doi.org/10.1007/s10902-009-9181-2

Proctor, C., Tsukayama, E., Wood, A. M., Maltby, J., Eades, J. F., \& Linley, P. A. (2011). Strengths gym: The impact of a character strengths-based intervention on the life satisfaction and wellbeing of adolescents. The Journal of Positive Psychology, 6(5), 377-388.

http://dx.doi.org/10.1080/17439760.2011.594079

Roffey, S. (2012). Positive relationships: Evidence based practice across the world. Dordrecht, The Netherlands: Springer. http://dx.doi.org/10.1007/978-94-007-2147-0

Seligman, M. (2011). Flourish: A new understanding of happiness, well-being-and how to achieve them. New York, NY: Free Press.

Seligman, M., Ernst, R., Gillham, J., Reivich, K., \& Linkin, M. (2009). Positive education: Positive psychology and classroom interventions. Oxford Review of Education, 35(3), 293-311. http://dx.doi.org/10.1080/03054980902934563

Sheldon, K. M., \& Elliot, A. J. (1998). Not all personal goals are personal: Comparing autonomous and controlled reasons for goals as predictors of effort and attainment. Personality and Social Psychology Bulletin, 24(5), 546-557.

Shoshani, A., \& Slone, M. (2013). Middle school transition from the strengths perspective: Young adolescents' character strengths, subjective wellbeing, and school adjustment. Journal of Happiness Studies, 14(4), 1163-1181. http://dx.doi.org/10.1007/s10902-012-9374-y

Sin, N. L., \& Lyubomirsky, S. (2009). Enhancing wellbeing and alleviating depressive symptoms with positive psychology interventions: A practice-friendly meta-analysis. Journal of Clinical Psychology: In Session, 65, 467-487. http://dx.doi.org/10.1002/jclp.20593

Snyder, C. R. (Ed.). (2000). Handbook of hope: Theory, measures, and applications. San Diego, CA: Academic Press.

Snyder, C. R., Harris, C., Anderson, J. R., Holleran, S. A., Irving, L. M., Sigmon, S. T., ... Harney, P. (1991). The will and the ways: Development and validation of an individual-differences measure of hope. Journal of Personality and Social Psychology, 60(4), 570-585. http://dx.doi.org/10.1037/0022$\underline{3514.60 .4 .570}$

Spence, G. B. (2007). GAS powered coaching: Goal Attainment Scaling and its use in coaching research and practice. International Coaching Psychology Review, 2(2), 155-167. 
Spence, G. B., Cavanagh, M. J. \& Grant, A. M. (2008). The integration of mindfulness training and health coaching: An exploratory study. Coaching: An International Journal of Theory, Research and Practice, 1(2), 145-163. http://dx.doi.org/10.1080/17521880802328178

Spence, G. B., \& Grant, A. M. (2005). Individual and group life-coaching: Initial findings from a randomised, controlled trial. Evidence-based Coaching, 1, 143-158.

Stober, D., \& Grant A. M. (2006). Toward a contextual approach to coaching models. In D. Stober, \& A. M. Grant (Eds.), Evidence-based coaching handbook. New York, NY: Wiley.

Tennant, R., Hiller, L., Fishwick, R., Platt, S., Joseph, S., Weich, S., ... Stewart-Brown, S. (2007). The Warwick-Edinburgh Mental Wellbeing Scale (WEMWBS): Development and UK validation. Health and Quality of Life Outcomes, 5(1), 1. http://dx.doi.org/10.1186/1477-7525-5-63

van Nieuwerburgh, C. (2012). Coaching in education: Getting better results for students, educators, and parents. London, United Kingdom: Karnac.

Waters, L. (2011) A review of school-based positive psychology interventions. The Australian Educational and Developmental Psychologist, 28(2), 754-90. http://dx.doi.org/10.1375/aedp.28.2.75

Waters, S. K., Lester, L., \& Cross, D. (2014). Transition to secondary school: Expectation versus experience. Australian Journal of Education, 58(2), 153-166. http://dx.doi.org/10.1177/0004944114523371

Whitmore, J. (2003). Coaching for performance. London, United Kingdom: Nicholas Brealey. 


\section{Appendix 1. Overview of student coaching program}

Week 1: Introduction

- Introduction to Coaching and the Program

- Aims of Program and Setting Group Rules

- Review - 'Roadmap of Coaching'

- Irritations Inventory Worksheet

- Identifying Needs and Values Worksheet

- Homework - Letter from the Future

Week 2: Goal setting

- Review - 'Smart Goals and How to Use Them in Coaching'

- Set Smart Goals x 2 - Using 'Letter from the Future' and 'Smart Goal Planning Guide'

- Complete 'Staying Motivated' Worksheet

- Complete 'Stages of Change' Worksheet

- Review -' House of Change'

Weeks 3-9: Ongoing coaching sessions

- Coaching Sessions - Use 'Introduction to the Grow Model/Structuring Coaching Sessions'

- Students to use 'Weekly Review Sheets'

Week 10: Conclusion and celebration

- Reflect on coaching progress

- Celebration of program completion

\section{Implementation}

1) Student booklet and laminated cards of 'GROW' model prepared

2) Student participants finalized, i.e., randomly selected using the randomization function in MS Excel

3) Trial began in February 2013 (approximately week 3/term 1)

4) Student participants completed nine sessions in total/50mins each (four sessions in term 1 and five sessions in term 2, including last celebration session)

5) Cognitive-Behavioral/Solution-Focused Coaching Intervention

a) Introduction

b) Understanding Change/Roadmap of Change

c) Goal Setting (Irritations Inventory)

d) Values Identification

e) Letter from the Future

f) GROW - A Model of Coaching

g) Student Co-Coaching (Solution Focused)

h) ANTS into PETS (Cognitive Behavioral)

i) Identifying Resources

j) Celebrating Success

6) Trial was completed June 2013 


\section{Appendix 2. Survey questions for life coaching trial}

Dear Year 11 student

During Terms 1 \& 2 of 2103 you have been involved in an Evidence-Based Life (or Personal) Coaching Project. The aim of the project was to improve academic outcomes and assist you in goal setting and implementation. The program consisted of a total of 9 sessions- 8 weeks of coaching and 1 session of reflection and celebration:

- Week 1-Intro to Coaching/Roadmap of Coaching/Irritations Inventory/Identifying Needs \& Values/Letter from the Future

- Week 2-The Grow Model/House of Change/Staying Motivated/Stages of Change

- Weeks 3 to 8-Coaching in Action, the Grow Model/Weekly Review Sheets

- Week 9-Reflection \& Celebration

To assist teachers in reviewing this project-please supply honest reflections to the following questions:

1) What aspects of the Coaching Trial did you find useful and why?

2) How would you rate the success of being on your way to achieve your 2 goals (1 academic/1 personal) from 1 to 10 ?

3) What new things have you learnt from this trial?

4) How would you now rate your confidence in setting and working towards individual goals- from 1 to 10 ?

5) How has this trial helped you personally?

6) What aspects of the program would you change and why?

7) Do you think this program would be beneficial for all year 11 students to participate in, over 2 terms?

8) Is there anything you would like to offer as a helpful comment/s? 